\title{
Association between Acute Stroke and Metabolic Syndrome-An Observational Study in a Tertiary Hospital
}

\author{
Razzak MA ${ }^{1}$, Kabir $\mathrm{MH}^{2}$, Naznin $\mathrm{F}^{3}$, Rahman $\mathrm{QAA}^{4}$ \\ DOI:https://doi.org/10.3329/jafmc.v16i2.55288
}

\begin{abstract}
Introduction: Stroke is one of the leading causes of death worldwide including Bangladesh. There are various modifiable and non-modifiable risk factors for stroke. Metabolic syndrome is an important factor amongst them.
\end{abstract}

Objective: To determine the association of stroke with metabolic syndrome.

Materials and Methods: This cross sectional study was carried out at Neurology Centre and Family Medical Ward of combined military hospital (CMH) Dhaka from July 2018 to December 2018. Total 100 admitted cases of acute stroke (both ischaemic and haemorrhagic) were enrolled. Diagnosis was confirmed by clinical examinations, relevant laboratory investigations and CT scan and/or MRI of brain. Verbal consent was obtained from patients or next of kin. Ethical issue was addressed. Data collection was done in a prescribed form by face to face interview, clinical findings and laboratory and imaging results. Statistical analysis was carried out by using SPSS v16.0. Chi square test was done to see the level of significance.

Results: Hypertension (HTN) was found in $54.6 \%$ of haemorrhagic stroke and $45.5 \%$ of ischemic stroke. Diabetes Mellitus (DM) was present in $40 \%$ of ischaemic stroke and $32 \%$ of haemorrhagic stroke. Abdominal obesity was present in 13 haemorrhagic stroke and only 4 ischaemic stroke cases. Fasting hyperglycaemia was found in 20 haemorrhagic stroke and 30 ischaemic stroke cases. Hypertriglyceridaemia was found in 33 ischaemic stroke and 18 haemorrhagic stroke cases. Low high density lipoprotein cholesterol (HDL-C) was found in 30 ischaemic stroke and 15 haemorrhagic stroke patients. Total 53 patients fulfilled the criteria of metabolic syndrome and 21 of them had 4 elements like HTN, DM, high triglyceride (TG), low HDL-C. Metabolic syndrome was present in 39 out of 54 ischaemic stroke and 14 out of 46 haemorrhagic strokes. There was significant association between metabolic syndrome and stroke especially in the ischaemic stroke ( $p$ value $<0.001$ ).

Conclusion: Proper control of hypertension and DM, correction of dyslipidemia, obesity and lifestyle modification, regular physical activity and healthy dietary habits all are necessary to reduce the prevalence of metabolic syndrome and cardiovascular death including stroke.
Key-words: Metabolic syndrome, Acute stroke, Ischaemic stroke, haemorrhagic stroke, Dyslipidaemia, Abdominal obesity.

\section{Introduction}

The World Health Organization (WHO) defines stroke as a syndrome of rapidly developing clinical sign of focal and global disturbance of cerebral function, persisting for at least 24 hours leading to death with no apparent cause other than vascular origin ${ }^{1}$. Stroke is the $3 r d$ most common cause of death in developed nations after cancer and ischemic heart disease ${ }^{2}$. It is the most common neurological emergency and is a major cause of morbidity and mortality ${ }^{3}$.

It is estimated that 25 million people suffer from stroke each year and as a result 5 million develop permanent disability. Five and a half million stroke death occur each year. Every year there are approximately 15.3 million new stroke and 39 million prevalent cases worldwide ${ }^{4}$. Direct \& indirect costs associated with stroke are estimated to be approximately $\$ 65.5$ billion $^{5}$. Age specific prevalence (34-45 years) of a population based study done in Bangladesh revealed 4.37 per 1000, which is higher than that of Taiwan, where the prevalence was reported 0.51 per 1000 in persons aged 35- 44 years ${ }^{6,7,8}$. The comparison indicates that the stroke prevalence in Bangladesh is much higher than the Asian far-east, commonly known for high prevalence of stroke ${ }^{9,10}$.

Stroke due to inadequate blood flow to part of the brain leads to cerebral infarction, whereas ruptured vessels in and around the brain lead to intracerebral haemorrhage ${ }^{10}$. Ischaemic stroke are commonly caused by atherosclerotic cardiovascular disease (ASCVD). On the other hand hypertension is the major risk factor for haemorrhagic stroke. Fixed risk factors are age, gender, race, heredity, previous vascular events \& high fibrinogen. Modifiable risk factors are high $\mathrm{BP}$, heart disease (AF, heart failure, endocarditis), DM, hyperlipidaemia, smoking, excess alcohol consumption, polycythaemia, oral contraceptives \& social deprivation ${ }^{11}$.

The metabolic syndrome (MetS) is a major and escalating public-health problem and clinical challenge worldwide in the wake of urbanization, surplus energy intake, increasing obesity, and sedentary life habits ${ }^{12}$. Metabolic syndrome is defined by a constellation of interconnected physiological, biochemical, clinical, and metabolic factors that directly increases the risk of cardiovascular

1. Brig Gen Md Abdur Razzak, MBBS, MCPS, FCPS, APLAR Clinical Fellow Rheumatology, Professor and Head, Department of Medicine, AFMC, Dhaka (E-mail: razzakprm@gmail.com) 2. Col Md Humayun Kabir, MBBS, FCPS (Medicine), FCPS (Neurology), Classified Specialist in Medicine and Neurologist, CMH, Dhaka 3. Maj Fateha Naznin, MBBS, Trainee in Medicine Grading Course, AFMI, Dhaka 4. Dr Quazi Audry Arafat Rahman, Assistant Registrar, Department of Medicine (AFMC), FCPS Part II Trainee, Kurmitola General Hospital, Dhaka. 
disease and type 2 diabetes mellitus. Insulin resistance, visceral adiposity, atherogenic dyslipidemia, endothelial dysfunction, genetic susceptibility, elevated blood pressure, hypercoagulable state, and chronic stress are the several factors which constitute the syndrome ${ }^{13}$.

There have been several definitions of MetS. The National Cholesterol Education Programme Adult Treatment Panel III (NCEP ATP-III) definition of the metabolic syndrome includes 3 or more of the following ${ }^{13}$.

1. $F B S \geq 100 \mathrm{mg} / \mathrm{dl}$

2. High $B P \geq 130 / 85 \mathrm{mmHg}$ or a history of HTN

3. $\mathrm{HDL}-\mathrm{C} \leq 40 \mathrm{mg} / \mathrm{dl}$ in men or $\leq 50 \mathrm{mg} / \mathrm{dl}$ in women

4. $T G \geq 150 \mathrm{mg} / \mathrm{dl}$

5. Waist circumference $\geq 102 \mathrm{~cm}$ for men $\& \geq 88 \mathrm{~cm}$ for women. In Asian population except Japan, waist circumference is $\geq 90 \mathrm{~cm}$ in men and $\geq 80 \mathrm{~cm}$ in women ${ }^{14,15}$. MetS confers a 5-fold increase in the risk of type 2 diabetes mellitus (T2DM) and 2-fold the risk of developing cardiovascular disease (CVD) over the next 5 to 10 years ${ }^{12}$. Further, patients with the MetS are at 2- to 4-fold increased risk of stroke ${ }^{16}$.

The relationship between the metabolic syndrome and ischaemic stroke has been well characterized. One large multiethnic prospective study found the metabolic syndrome to be significantly associated with an increased risk of ischaemic stroke ${ }^{17}$. But there is not much research in Bangladesh in this field. The present study is aimed to find the association between acute stroke and metabolic syndrome.

\section{Materials and Methods}

This cross sectional study was conducted from July 2018 to December 2018 among 100 acute stroke patients who were admitted in Neurology Centre and Family medicine ward, CMH Dhaka. Random sampling method was used in the study.

\section{Inclusion criteria}

- $\quad$ Admitted with sudden onset of characteristic neurological deficit.

- Having distinctive neurological signs reflecting the regions of brain involved.

- $\quad$ CT scan of brain showing infarction or haemorrhage.

- $\quad$ Agreed to give consent.

Exclusion criteria

- Patients with loss of consciousness due to head injury, metabolic coma, poisoning or epilepsy.

- CT scan showing anything other than infarct or haemorrhage e.g. tumour, inflammatory lesion, traumatic lesion.

A semi-structural questionnaire was followed by face to face interview on the basis of objective of the study. Statistical analysis was carried out by using SPSS v16.0. Descriptive statistics were used for the interpretation of the findings. Chi-square test $(X 2)$ was done to measure the level of significance, $p=<0.05$ was considered as significant. Ethical issue was addressed.

\section{Results}

Out of 100 stroke patients $72(72 \%)$ were diabetic. Out of 66 hypertensive stroke patients 36 (54.55\%) had haemorrhagic stroke and 30 (45.45\%) had ischaemic stroke. 26 (26\%) stroke patients developed electrolyte imbalance. Among them 19 had ischemic stroke and 07 had hemorrhagic stroke. There is no significant association between type of stroke and DM, HTN \& electrolyte imbalance (Table-I).

Out of 21 patients of having previous history of stroke, 10 (47.6\%) had history of ischaemic stroke and 11 patients had haemorrhagic stroke (52.4\%)(Figure-1). Majority (54\%) patients had ischaemic stroke, $44 \%$ had intracerebral haemorrhage and only $2 \%$ had subarachnoid haemorrhage (SAH) (Figure-2). Out of total 17 abdominal obesity cases, 13(76.5\%) were ischaemic stroke and $4(23.5 \%)$ haemorrhagic stroke (Figure-3). There is no significant association between fasting blood sugar, serum triglyceride and HDL-C with type of stroke (Table-II). It is revealed from this study that total 53 patients had metabolic syndrome. Among them maximum number of patients (21\%) had HTN, raised FBS and dyslipidaemia followed by $11(11 \%)$ patients had raised $B P$, FBS and TG level. HTN, abdominal obesity, sugar and TG were raised in $9(9 \%)$ of those patients. $5(5 \%)$ of them had all the criteria of metabolic syndrome (Table-III). There is a significant association found between metabolic syndrome and type of stroke, especially with the ischaemic stroke $(x 2=13.07, d f=1, p=<0.001)$ (Table-IV).

Table-I: Association of DM, HTN and electrolyte imbalance with different types of stroke $(n=100)$

\begin{tabular}{|c|c|c|c|c|}
\hline & \multicolumn{2}{|c|}{ Number of patients } & \multirow{2}{*}{$\begin{array}{c}\text { Percentage } \\
(\%)\end{array}$} & \multirow{2}{*}{$\begin{array}{c}P \\
\text { value }\end{array}$} \\
\hline & Ischaemic & Haemorrhagic & & \\
\hline Diabetic & 40 & 32 & $72(72 \%)$ & \multirow{9}{*}{$>0.05$} \\
\hline Non-diabetic & 14 & 14 & $28(28 \%)$ & \\
\hline Total & 54 & 46 & $100 \%$ & \\
\hline Hypertensive & 30 & 36 & $66(66 \%)$ & \\
\hline Normotensive & 24 & 10 & $34(34 \%)$ & \\
\hline Total & 54 & 46 & $100 \%$ & \\
\hline $\begin{array}{l}\text { Electrolyte } \\
\text { imbalance present }\end{array}$ & 19 & 7 & $26(26 \%)$ & \\
\hline Electrolyte & 35 & 39 & $74(74 \%)$ & \\
\hline Total & 54 & 46 & $100 \%$ & \\
\hline
\end{tabular}

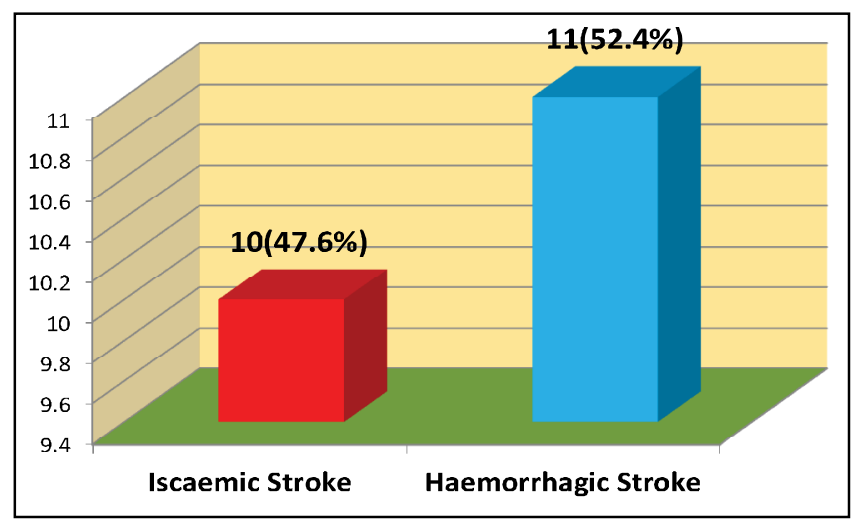

Figure-1: Previous history of stroke $(n=21)$ 


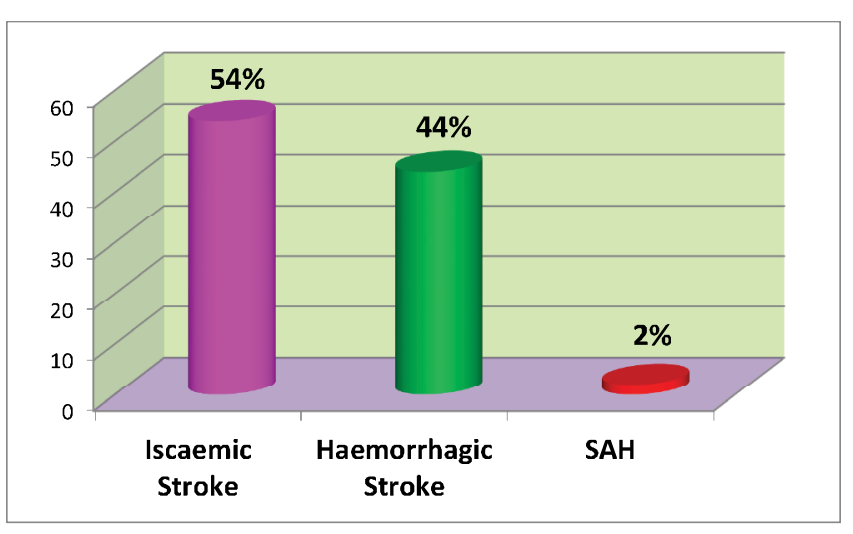

Figure-2: Type of stroke according to CT scan findings ( $n=100)$

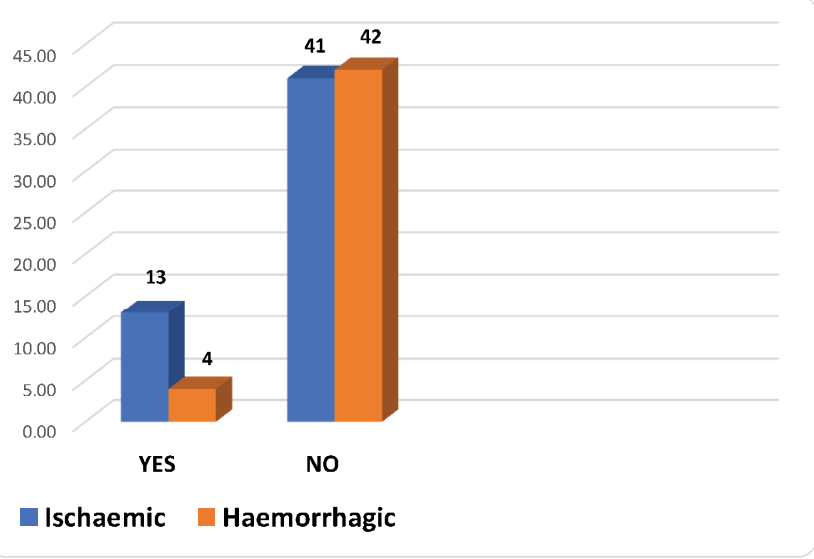

Figure-3: Frequency of abdominal obesity in stroke patients $(n=100)$

Table-II: Association of FBS, serum triglyceride and HDL-C with types of stroke $(n=100)$

\begin{tabular}{|c|c|c|c|c|}
\hline & \multicolumn{2}{|c|}{ Number of patients } & \multirow{2}{*}{$\begin{array}{c}\text { Percentage } \\
\text { (\%) }\end{array}$} & \multirow{2}{*}{$\begin{array}{c}P \\
\text { value }\end{array}$} \\
\hline & Ischaemic & Haemorrhagic & & \\
\hline $\mathrm{FBS} \geq 100 \mathrm{mg} / \mathrm{dl}$ & 30 & 20 & $50(50 \%)$ & \\
\hline $\mathrm{FBS}<100 \mathrm{mg} / \mathrm{dl}$ & 24 & 26 & $50(50 \%)$ & \\
\hline Total & 54 & 46 & $100 \%$ & \\
\hline $\begin{array}{l}\text { Raised S. TG } \\
\text { level }\end{array}$ & 33 & 18 & 51(51\%) & $>0.05$ \\
\hline Normal TG level & 21 & 28 & 49(49\%) & \\
\hline Total & 54 & 46 & $100 \%$ & \\
\hline Low HDL-C & 30 & 15 & $45(45 \%)$ & \\
\hline High HDL-C & 24 & 31 & $55(55 \%)$ & \\
\hline Total & 54 & 46 & $100 \%$ & \\
\hline
\end{tabular}

Table-III: Distribution of patients in the category of metabolic syndrome $(\mathrm{n}=53)$

\begin{tabular}{|c|c|c|c|c|c|}
\hline HTN & $\begin{array}{c}\text { Abdominal } \\
\text { obesity }\end{array}$ & $\begin{array}{c}\text { FBS } \geq 100 \\
\text { mg/dl }\end{array}$ & $\begin{array}{c}\text { Low } \\
\text { HDL-C }\end{array}$ & $\begin{array}{c}\text { Raised S. } \\
\text { TG level }\end{array}$ & $\begin{array}{c}\text { Total } \\
\text { numbers (n) }\end{array}$ \\
\hline+ & & + & & + & 11 \\
+ & + & + & + & + & 5 \\
& + & + & & + & 3 \\
+ & & + & + & + & 21 \\
+ & + & + & & + & 9 \\
+ & & & + & + & 4 \\
\hline 50 & 17 & 49 & 30 & 44 & Total=53 \\
\hline
\end{tabular}

Table-IV: Association of Metabolic syndrome in haemorrhagic and ischaemic stroke $(n=100)$

\begin{tabular}{|l|c|c|c|l|}
\hline Type of stroke & $\begin{array}{c}\text { Metabolic } \\
\text { syndrome } \\
\text { present }\end{array}$ & $\begin{array}{c}\text { Metabolic } \\
\text { syndrome } \\
\text { absent }\end{array}$ & Total & p value \\
\cline { 1 - 4 } Haemorrhagic & 14 & 32 & 46 & \multirow{2}{*}{$<0.001$} \\
\cline { 1 - 4 } Ischaemic & 39 & 15 & 54 & \\
\cline { 1 - 4 } Total & 53 & 47 & 100 & \\
\hline
\end{tabular}

\section{Discussion}

Stroke incidence usually rises exponentially with increasing age. An European study revealed peak incidence of stroke between the age of 50-69 years ${ }^{18}$. Again two groups of researcher found peak incidence of stroke between 5 th to 7 th decades ${ }^{19-20}$. This present study coincided with all above.

Present study showed that 66 stroke patients were hypertensive. Among them, 30(45.5\%) hypertensive patients had hemorrhagic stroke and $36(54.6 \%)$ had ischemic stroke but there was no statistical association between HTN and type of stroke ( $p>0.05)$. Millions et al showed that $31 \%$ patients with cerebral infarcts had HTN ${ }^{14}$.

In this study 21 patients had a previous history of stroke. Among them $10(47.6 \%)$ were suffering from ischemic stroke and 11 $(52.4 \%)$ were suffering from hemorrhagic stroke. A western study ${ }^{21}$ showed that $18 \%$ patient suffered acute stroke had past history of stroke, which is similar to present study.

In this study, 26 patients (24\%) of acute stroke developed electrolyte imbalance. Among them 19 (73.0\%) had ischemic stroke and 07 (26.9\%) had hemorrhagic stroke which is not statistically significant $(p>0.05)$. In a study by Kabir A et a $\mathrm{l}^{22}$ found that $52 \%$ hemorrhagic stroke $(p<0.01)$ and $26 \%$ ischemic stroke patients $(p>0.05)$ had dyselectrolytaemia which is not consistent with this study.

In this study, abdominal obesity found in 17 stroke patients. Among them, 13 (76.5\%) had ischemic stroke and 4 (23.5\%) had hemorrhagic stroke. There was no significant relationship between abdominal obesity and acute stroke or type of stroke. The Nurses' Health Study showed that women with increased BMI had an increased risk of ischemic stroke but not after adjustment of HTN, DM and high cholesterol ${ }^{9}$. In contrast, other studies had failed to find an independent relationship between abdominal obesity and increased risk of stroke in women ${ }^{23-26}$ or men ${ }^{27,28}$. Therefore, the association of obesity with stroke remains controversial. These findings are very close to above studies.

In this study, out of 100 patients 72 patients were diabetic. The Copenhagen stroke study has shown that in 1135 acute stroke patients, 233 (20\%) were having $\mathrm{DM}^{29}$. In this study high incidence is due to lack of awareness about DM and there may be reactionary rise of blood glucose in acute stress. 
Serum Triglyceride level was high in 51 of all acute stroke patients. Among them ischemic stroke patients had more high TG level -33 (64.7\%) than hemorrhagic patients- 18 (36.7\%). Another western study found that elevated level of TG appears to be associated with increased risk of ischemic stroke ${ }^{30}$.

In this study total 45 patients had low HDL-C in which ischemic stroke $30(66.7 \%)$ patients had more low level of HDL-C than hemorrhagic stroke. A negative association between HDL-C level and risk of stroke or transient ischemic attacks has been found in a case-control study ${ }^{29}$. In the Freirberg's study, an inverse relation was identified between HDL-C and athero-thrombotic brain infarction among men ${ }^{21}$.

In this study, more than half (53\%) of all stroke patients had metabolic syndrome. The metabolic syndrome prevalence was $57 \%$ among the entire population and $64 \%$ among the ischemic stroke in a published study ${ }^{22}$. The most prevalent metabolic syndrome component was HTN followed by DM. These findings are very close to this study.

Some researcher found metabolic syndrome among admitted stroke patients was $48 \% \%^{16}$. In other studies among patients with ischemic stroke prevalence of metabolic syndrome were found between $40 \%$ and $50 \%^{31-33}$. In this study among 54 ischemic stroke patients, 39(72\%) had metabolic syndrome and among 46 hemorrhagic stroke patients, only 14(30.4\%) patients had metabolic syndrome. Metabolic syndrome is associated with higher risk of stroke and similar or higher risk than elevated FBS alone or hypertensive alone ${ }^{34,35}$. These findings suggest that metabolic syndrome was associated with an increased incidence of stroke. This result correlated with a study in Japan ${ }^{26}$.

The result of the present study should be interpreted in the light of the following limitations. First, the sample size was relatively small. Second, there was a chance of reactionary rise of BP and blood glucose level during acute stress. However, the main analysis of the present study was focused to find out relationship between presences of metabolic syndrome in acute stroke patients.

\section{Conclusion}

Stroke is one of the foremost causes of morbidity, mortality and a socio-economic challenge; more so in Bangladesh where health system including the rehabilitation is not within the reach of ordinary people. Individual factor of metabolic syndrome is not significant to determine the type of stroke; but in combination of multiple factors when fulfill the criteria of metabolic syndrome, it has significant association with acute stroke, especially the ischaemic type. In this study, direct and strong association between metabolic syndrome and acute stroke was found. Despite some limitations like small sample size, single centered study etc; this study can give an utmost picture of the disease in a tertiary care hospital of Bangladesh. In a developing country like ours the best policy for combating stroke is primary prevention of the risk factors and awareness.

\section{References}

1. Harmsen K, Hatano P, Marquardsen S et al. Cerebrovascular disease in the community. Result of WHO collaborative study. Bull WHO. 1980; 58(1):113-30.

2. Allen $\mathrm{CMC}$, Lueck CJ, Dennis M. Neurological disease. In Colledge NR (ed). Davidson's Principal and Practice of Medicine, 23rd edition. UK Churchill Livingstone Elsevier.2014:1131-1235.

3. Bergen DC. The worldwide burden of neurologic disease. Neurology. 1996; 47:21-50.

4. Rothwell PM, coull AJ, Giles MF et al. Changes in stroke medicine, incidence, mortality, case fatality. Lancet. 2007; 363:1925-33.

5. Thomso R. Evidence based on implementation of complex interventions risk. BMJ. 1999; 6(4):207-11.

6. Kristensen B, Malam J Carlberg B et al. Epidemiology and etiology of ischemic stroke in young adults aged 18-44 years in North Sweden. Stroke. 1997; 28:1702-9.

7. Bogousslavsky S, Peierre P. Ischemic strokes under age 45. Neuroclin. 1992; 10:113-24.

8. Siddique AN, Zannatun N, Mahbub MS et al. Clinical presentation and epidemiology of stroke- A study of 100 cases. J Medicine. 2009; 10:86-9.

9. Summers D, Leonard A, Wentworth D et al. Comprehensive overview of nursing and interdisciplinary care of the acute ischemic stroke patient: A scientific statement from the American Heart Association. Stroke. 2009; 40(8):2911-44.

10. Fauci AS Braundwald E, Kasper DL et al. Harrison's Manual of Medicine 20th ed, 2009:699-700.

11. Grundy SM Cleeman JI, Daniels SR et al. for the American Heart Association; National Heart, Lung and Blood Institute Diagnosis and Management of the Metabolic Syndrome. Circulation. 2005; 112(17):2735-52.

12. Alberti KGMM, Eckel RH, Grundy SM et al. Harmonizing the metabolic syndrome: A joint interim statement of the international diabetes federation task force on epidemiology and prevention; National heart, lung, and blood institute; American heart association; World heart federation; International atherosclerosis society; And international association for the study of obesity. Circulation. 2009; 120(16):1640-5.

13. Kaur J. A Comprehensive Review on Metabolic Syndrome. Cardiol Res Pract. 2014; 2014:943162.

14. Millions HJ, Rizos E, Goudevenos J et al. Components of the metabolic syndrome and risk for first ever ischemic non-embolic stroke in elderly subjects. Stroke. 2017; 36:1372-6.

15. Furie KL, Kanser SE, Adams RS et al. Guidelines for the prevention of stroke in patients with stroke and transient ischemic attack: A guideline for healthcare professionals from the 
American Heart Association/ American Stroke Association. Stroke. 2017; 42:09-10.

16. Olijhoek JK, Van Der Graaf Y, Banga JD et al. The Metabolic Syndrome is associated with advanced vascular damage in patients with coronary heart disease, stroke, peripheral arterial disease or abdominal aortic aneurysm. European Heart Journal. 2004; 25(4):342-8.

17. Wannamethee SG, Shaper AG, Lennon $L$ et al. Metabolic syndrome vs Framingham Risk Score for prediction of coronary heart disease, stroke, and type 2 diabetes mellitus. ARCH med intern 2005; Arch Intern Med. 2005; 165(22):2644-50.

18. Carlo AD, Lamassa M, Marzia Baldereschi $M$ et al. Risk factors and outcome of subtypes of ischemic stroke. Data from a multicenter multinational hospital-based registry. The European Community Stroke Project. J Neurol Sci. 2006; 244(1-2):143-50.

19. Edgell R, Yavagal DR. Acute endovascular stroke therapy. Curr Neurol Neurosci Rep. 2006; 6(6):531-8.

20. Einhorn D, Reaven GM, Cobin RH et al. American College of Endocrinology position statement on the insulin resistance syndrome. Endocr Pract. 2003; 9(3):237-52.

21. Freirberg JJ, Hansen AT, Jensen JS et al. Nonfasting triglycerides and risk of ischemic stroke in the general population. JAMA. 2008; 300(18):2142-52.

22. Kabir A, Sadeka MM, Ahmed JM et al. Frequency of metabolic syndrome among stroke patients admitted in Mitford Hospital. J Medicine. 2008; 9(1):37-41.

23. Wannamethee SG, Shaper AG, Lennon L. Metabolic Syndrome vs Framingham Risk Score for Prediction of Coronary Heart Disease, Stroke and Type 2 Diabetes Mellitus. Arch Intern Med. 2005; 165(22):2644-50.

24. Niwa $Y$, Ishikawa $S$, Gotoh $T$ et al. Association between Stroke and Metabolic Syndrome in a Japanese Population: Jichi Medical School (JMS) Cohort Study. J Epidemiol. 2010; 20(1):62-9.
25. Hakim M, Hayee MA, Saha CK et al. Socio-demographic study of posterior circulation stroke survival. JCMCTA. 2009; 20(1):23-6.

26. Kusuda K, Saku Y, Sadoshima S et al. Disterbances of fluid and electrolyte balance in patients with acute stroke. Nippon Ronen Igakkai Zasshi. 1989; 26(3):223-7.

27. Folsom AR, Prineas RJ, Kaye SA et al. Incidence of hypertension and stroke in relation to body fat distribution and other risk factors in older women. Stroke. 1990; 21(5):701-6

28. Lapidus L. Distribution of adipose tissue and risk of cardiovascular disease and death: A 12 year follow up of participants in the population study of women in Gothenburg, Sweden. Br Med J (Clin Res Ed). 1984; 289:1257.

29. Jørgensen $\mathrm{H}$, Nakayama $\mathrm{H}, \mathrm{Raaschou} \mathrm{HO}$ et al. Stroke in patients with diabetes. The Copenhagen Stroke Study. Stroke. 1994; 25(10):1977-84.

30. Gordon T, Kannel WB, Castelli WP et al. Lipoproteins, cardiovascular disease, and death: The Framingham Study. Arch Intern Med. 1981; 141(9):1128-31.

31. Boden-Albala B: Current understanding of multiple risk factors as the metabolic syndrome: distillation or deconstruction. Semin Neurol. 2006, 26:108-16.

32. Chimonitz MI, Lynn MK, Howlett-Smith $\mathrm{H}$ et al. Comparison of warfarin and aspirin for symptomatic intracranial arterial stenosis. N ENGL Med. 2005; 352(13):1305-16.

33. Dosamond $W$, Fegal $K$ Furie $K$ et al. Heart Disease and Stroke Statistics; 2011 updates: A report from the American Heart Association Statistics Committee \& Stroke Statistics Subcommittee. Circulation. 2013; 117:25-146.

34. American Heart Association. Heart disease and strokes statistics-2007 update. Circulation. 2007; 115(5):e69-e171.

35. WHO definition pub no- WHO/NCD/NCS/99.2 